\title{
Dynamic remodeling of endometrial extracellular matrix regulates embryo receptivity in cattle
}

\author{
Saara Carollina Scolari ${ }^{1}$, Guilherme Pugliesi ${ }^{1}$, Ricardo de Francisco Strefezzi ${ }^{2}$, Sónia Cristina da \\ Silva Andrade ${ }^{3}$, Luiz Lehmann Coutinho ${ }^{3}$ and Mario Binelli ${ }^{1}$ \\ ${ }^{1}$ Department of Animal Reproduction, FMVZ-USP, Pirassununga, SP, Brazil, ${ }^{2}$ Department of Veterinary Medicine, \\ FZEA-USP, Pirassununga, SP, Brazil and ${ }^{3}$ Department of Animal Science, ESALQ-USP, Piracicaba, SP, Brazil
}

Correspondence should be addressed to M Binelli; Email: binelli@usp.br

\begin{abstract}
We aimed to evaluate in the bovine endometrium whether (1) key genes involved in endometrial extracellular matrix (ECM) remodeling are regulated by the endocrine peri-ovulatory milieu and (2) specific endometrial ECM-related transcriptome can be linked to pregnancy outcome. In Experiment 1, pre-ovulatory follicle growth of cows was manipulated to obtain two groups with specific endocrine peri-ovulatory profiles: the Large Follicle-Large CL group (LF-LCL) served as a paradigm for greater receptivity and fertility and showed greater plasma pre-ovulatory estradiol and post-ovulatory progesterone concentrations compared to the Small Follicle-Small CL group (SF-SCL). Endometrium was collected on days 4 and 7 of the estrous cycle. Histology revealed a greater abundance of total collagen content in SF-SCL on day 4 endometrium. In Experiment 2, cows were artificially inseminated and, six days later, endometrial biopsies were collected. Cows were retrospectively divided into pregnant and non-pregnant (P vs NP) groups after diagnosis on day 30. In both experiments, expression of genes related to ECM remodeling in the endometrium was studied by RNAseq and qPCR. Gene ontology analysis showed an inhibition in the expression of ECM-related genes in the high receptivity groups (LF-LCL and P). Specifically, there was downregulation of TGFB2, ADAMTS2, 5 and 14, TIMP3 and COL1A2, COL3A1, COL7A1 and COL3A3 in the LF-LCL and P groups. In summary, the overlapping set of genes differently expressed in both fertility models: (1) suggests that disregulation of ECM remodeling can impair receptivity and (2) can be used as markers to predict pregnancy outcome in cattle.

Reproduction (2017) 153 49-61
\end{abstract}

\section{Introduction}

The establishment and maintenance of pregnancy are complex events that require a fine-tuned synchrony between a receptive maternal uterus and the embryo's ability to develop in such an environment. The development of histologically and functionally normal endometrium is critical for endometrial receptivity and the initial embryo-maternal interactions. In this context, endometrial tissue remodeling might be a prerequisite to obtain the optimal uterine environment for the early embryo, as previously documented in mice and human studies. When focusing on endometrial morphology, the endometrial extracellular matrix (ECM) has crucial importance; it is the non-cellular component found in all tissues and organs providing physical support for the uterine cells. The ECM is a highly dynamic structure, under constant remodeling by enzymatic or non-enzymatic means to maintain tissue homeostasis (Jarvelainen et al. 2009, Schmidt \& Friedl 2010).

Three major classes of biomolecules belong to the ECM: structural proteins (such as collagen and elastin), specialized proteins (such as fibrilins, fibronectines and laminin) and proteoglycans (Alberts et al. 2002, Kim et al. 2011). The ECM's main three functions are: (1) structural, by filling the extracellular spaces of tissues; (2) functional, by mediating cell adhesion, growth, migration and differentiation and (3) regulatory, by controlling the release of growth factors and cytokines by the action of peptidases that can modulate cell physiology (Schenk \& Quaranta 2003, Mott \& Werb 2004, Jarvelainen et al. 2009).

The abundance of endometrial ECM proteins is finely controlled by synthesis and proteolytic degradation. Disturbance of such a critical balance may result in implantation abnormalities and, consequently, infertility (Skinner et al. 1999). Several proteases are involved in the proteolytic degradation of ECM proteins, but the most prominent are the members of the family of matrix metalloproteinases (MMP), disintegrins and metalloproteinases (ADAM), ADAMTS (a disintegrin and metalloprotease with a thrombospondin motif) and their inhibitors (TIMPs) (Reiss \& Saftig 2009, Egeblad et al. 2010). 
In cattle, the role of ECM remodeling in reproductive processes is poorly understood as only few studies were performed in ruminants at the implantation period (Guillomot 1999, Boos 2000, Yamada et al. 2002, Mishra etal.2010). Most reports on the essence of ECM remodeling for endometrial receptivity and fertility originate from human and rodent studies (Farrar \& Carson 1992, Clark et al. 1993, Das et al. 1997, Hurst \& Palmay 1999). Mishra and coworkers (2010) studied the expression pattern of MMPs and described the bovine mechanism of ECM regulation pointing to MMPs and ECM metalloproteinase inducer (EMMPRIN) in the endometrium of cyclic and pregnant cows. They showed an attenuated expression of these molecules in day 19 pregnant in comparison to cyclic endometrium. Ulbrich and coworkers (2011) stressed the importance of high endometrial MMP2 enzymatic activity during the elongation phase of the blastocyst, which may increase the availability of growth factors supporting conceptus development. The latter researchers suggested that an increased TIMP2 abundance in the uterine fluid during trophoblast elongation points to a well-balanced ECM integrity, needed for the maintenance of pregnancy (Ulbrich et al. 2011).

However, clear information on how the ECM remodeling events can be linked to maternal receptivity in cattle is lacking. This highlights the need to gain more insights in the factors regulating the ECM remodeling in the endometrial tissue during early diestrus. In this regard, sexual steroid hormones are key regulatory factors of the endometrial tissue and abundance and distribution changes of specific collagen types across the estrous cycle was reported previously (Boos 2000). Indeed, greater pre-ovulatory estradiol and postovulatory progesterone concentrations are associated with increased bovine embryo survival (Perry et al. 2005, Meneghetti et al. 2009, Peres et al. 2009, Dadarwal et al. 2013). The endometrium expresses both progesterone and estradiol receptors and endometrial functions are modulated by changes in sex steroid concentrations to support conceptus growth and pregnancy maintenance (Robinson et al. 2001, Bazer \& Slayden 2008). Reports by Klein and coworkers (2006), Forde and coworkers (2009), Bauersachs and coworkers (2006), Mamo and coworkers (2011), among others, used holistic transcriptomic approaches to understand changes in endometrial function in response to the growing conceptus. In general, conceptus-induced changes are initially observed after initial elongation (i.e., 12-13 days after estrus), and most clearly at maternal recognition of pregnancy (15-17 days after estrus). Despite their critical importance, specific biological processes and molecular pathways affected by peri-ovulatory variations in sex steroids (from proestrus to early diestrus; i.e., 7 days after estrus), are only now starting to be elucidated and have not been sufficiently studied and explored in the endometrium. Most importantly, at least in nonbovine species, ECM remodeling is regulated by steroid hormones (Crawford \& Matrisian 1996, Schroen \& Brinckerhoff 1996, Zhang \& Salamonsen 2002).

In this study, we hypothesize that the level of ECM remodeling events can be regulated by specific endocrine profiles associated with receptivity. Furthermore, we propose that the ECM transcript signature during early pregnancy has a direct relationship with the probability of pregnancy success in cows. Therefore, two bovine fertility models were used to study: (i) the effect of endocrine profiles during peri-ovulatory period on ECM remodeling events on endometrial tissue collected on days 4 and 7 of the estrous cycle and (ii) whether ECM characteristics on day 6 uterine biopsies can be associated to pregnancy outcome. To the best of our knowledge, these are the earliest time points after estrus that was investigated for endometrial events related to receptivity in beef cattle.

\section{Materials and methods}

\section{Animals}

Animal procedures were approved by the Ethics and Animal Handling Committee of the School of Veterinary Medicine and Animal Science of the University of São Paulo. The experiments were conducted at the University of São Paulo, campus Pirassununga, SP, using adult Nelore (Bos indicus) cows, pluriparous, cyclic, non-lactating, without reproductive disorders detectable by gynecological examination and body condition score between 3 and 4 ( 0 emaciated; 5 obese). All animals were kept in grazing conditions and supplemented with sugar cane and/or corn silage, concentrate and minerals to fulfill their maintenance requirements and water ad libitum.

\section{Experiment 1. Reproductive management and experimental design}

\section{Study 1}

Ovulations were synchronized as described previously by Mesquita and coworkers (2014). The goal was to manipulate the peri-ovulatory endocrine milieu to obtain two groups of animals with distinct pre-ovulatory follicle (POF) and CL sizes and, consequently, contrasting peri-ovulatory endocrine milieus with distinct proestrus/estrus concentrations of E2 and diestrus concentrations of P4. This experimental model was used as a paradigm for lower (Small Follicle-Small CL group; SF-SCL) or greater (Large Follicle-Large CL group; LF-LCL) receptivity and fertility by our group (Perry et al. 2005, Peres et al. 2009, Meneghetti et al. 2009, Dadarwal et al. 2013, Pugliesi et al. 2016). Briefly, animals were pre-synchronized by two intramuscular (i.m.) injections of prostaglandin $\mathrm{F} 2 \alpha$ analogue (PGF2 $\alpha$; $0.5 \mathrm{mg}$ of sodium cloprostenol; Sincrocio, Ourofino Saúde Animal, Cravinhos, Brazil), 14 days apart. At the second PGF2 $\alpha$ injection of Presynch (D-20), animals received an Estrotect Heat detector patch (Rockway, Inc., Spring Valley, WI, USA) device, and estrus detection was performed twice daily from D-19 to D-16 and once daily from D-15 to D-10. Only animals that presented estrus after 


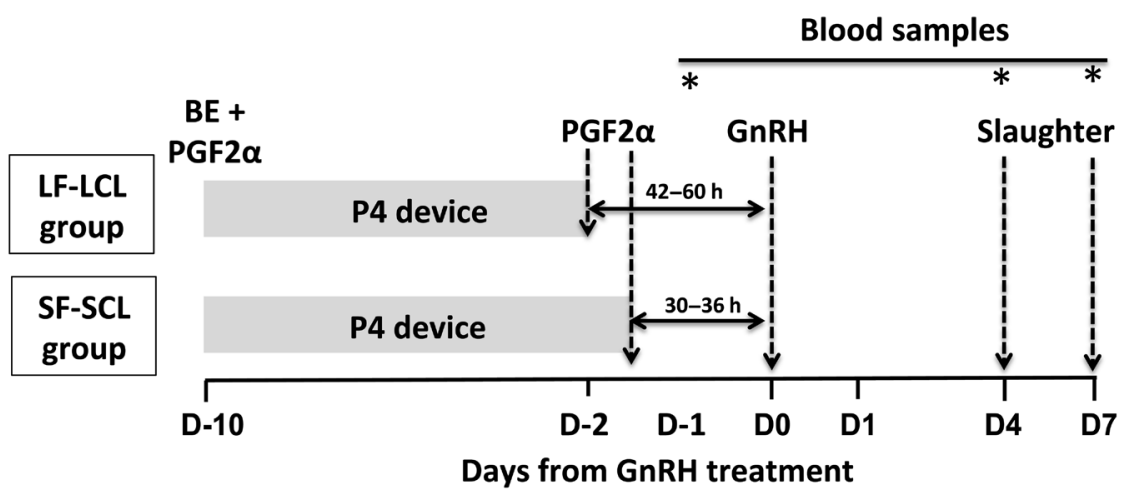

Figure 1 Experimental design to obtain samples from groups with Large Follicles and CL (LF-LCL) or Small Follicles and CL (SF-SCL). Cows were pre-synchronized via two injections of prostaglandin F2 $\alpha$ (PGF2 $\alpha ; 0.5 \mathrm{mg}$ of sodium cloprostenol) given 14 days apart. On D-10, cows received a progesterone-releasing device ( $1 \mathrm{~g}$; Sincrogest; Ourofino) and an injection of 2 mg estradiol benzoate (BE; Sincrodiol, Ourofino). On D-10, cows in the Large-Follicle and Large-CL group (LF-LCL) also received an injection of PGF2 $\alpha$. On the day the progesterone-releasing device was removed, all cows received PGF2 $\alpha$. On D0 ovulation was induced with $1 \mu \mathrm{g}$ of gonadotropin-releasing hormone analog $(\mathrm{GnRH}$; buserelin acetate; Sincroforte, Ourofino Saúde Animal). Cows were slaughtered on D4 (Study 1) or D7 (Study 2), reproductive tract was collected and dissected. An asterisk (*) indicates the moment of blood sampling.

the second PGF2 $\alpha$ treatment and with a new PGF-responsive $\mathrm{CL}$ (at least 5 days old) on D-10 stayed in the experiment. Therefore, the remaining cows $(n=41)$ received a new intravaginal P4-releasing device (1 g; Sincrogest, Ourofino) on D-10 along with an i.m. injection of $2 \mathrm{mg}$ estradiol benzoate (Sincrodiol, Ourofino Saúde Animal; Fig. 1). Simultaneously on D-10, cows from the LF-LCL group received a single i.m. treatment of PGF $2 \alpha$. The P4 devices were removed eight days later and $42-60 \mathrm{~h}$ or $30-36 \mathrm{~h}$ before the gonadotropin-releasing hormone $(\mathrm{GnRH})$ treatment in the LF-LCL $(n=20)$ and SF-SCL $(n=21)$ groups respectively. All animals received a PGF2 $\alpha$ injection at P4 device removal. Ovulations were induced in all cows on D0 using GnRH agonist (Buserelin acetate, $10 \mu \mathrm{g}$, i.m.; Sincroforte, Ourofino Saúde Animal) on D0. Expectation was that POF growth would be reduced in the presence of greater circulating P4 concentrations in cows from the SF-SCL group because of $\mathrm{P} 4$ from both exogenous (device) and endogenous $(\mathrm{CL})$ sources.

To assess follicle growth and ovulation of the POF and $\mathrm{CL}$ area and blood flow, transrectal ultrasound examinations were carried out on D-10 and D-6, daily from D-2 to D0 and from D3 to D7, and every $12 \mathrm{~h}$ on D1 to D2. Ultrasound exams were performed with the aid of a duplex B-mode (gray-scale) and Color-Doppler instrument (MyLab30 Vet

Table 1 Characteristics of the primers used in the measurements of transcripts related to endometrial extracellular matrix remodeling.

\begin{tabular}{|c|c|c|c|c|}
\hline Gene & Gene symbol & Representative ID & Sense primer & Antisense primer \\
\hline $\begin{array}{l}\text { ADAM metallopeptidase } \\
\text { with thrombospondin } \\
\text { type } 1 \text { motif, } 1\end{array}$ & ADAMTS1 & NM_001101080.1 & CAGGAACTGGAAGCCTAAAAA & GAGAACAAGGTCAGAAGGAGTG \\
\hline $\begin{array}{l}\text { ADAM metallopeptidase } \\
\text { with thrombospondin } \\
\text { type } 1 \text { motif, } 2\end{array}$ & ADAMTS2 & NM_174631.2 & СТССАТСССАGGСТACAATAAG & GCATTGGTGCTGGAAGTATG \\
\hline $\begin{array}{l}\text { ADAM metallopeptidase } \\
\text { with thrombospondin } \\
\text { type } 1 \text { motif, } 5\end{array}$ & ADAMTS5 & NM_007038.3 & GTGGTCGGAACCTTCAATAA & GGCTAAGTAGGCAGTGAATC \\
\hline $\begin{array}{l}\text { ADAM metallopeptidase } \\
\text { with thrombospondin } \\
\text { type } 1 \text { motif, } 14\end{array}$ & ADAMTS 14 & NM_080722.3 & GGGACAGGTCCATCTTCT & TCTAGGCTCAAGGTCTTCTT \\
\hline Matrix metallopeptidase 2 & MMP2 & NM_174745.2 & CCCAGACAGTGGATGATGC & TTGTCCTTCCTCCCAGGGTC \\
\hline Matrix metallopeptidase 14 & MMP14 & NM_174390.2 & TGCCGAGCСTTGGACTGT & GCCACCAGAAAGATGTCATTCC \\
\hline $\begin{array}{l}\text { Transforming growth factor, } \\
\text { beta } 1\end{array}$ & TGFB1 & NM_001166068.1 & ССТGСTGAGGCTCAAGTTAAAG & GCСАСТGCСGСАСААСТСС \\
\hline $\begin{array}{l}\text { Transforming growth factor, } \\
\text { beta } 2\end{array}$ & TGFB2 & NM_001113252.1 & AATTTGGTGAAGGCCGAGTTC & GGTTTTCACGACTTTGCTCCA \\
\hline $\begin{array}{l}\text { Transforming growth factor, } \\
\text { beta } 3\end{array}$ & TGFB3 & NM_001101183.1 & TTACTGCTTCCGCAATTTCA & TCTGAGCTGCGGAGGTATG \\
\hline Metallopeptidase inhibitor 1 & TIMP1 & NM_174471.3 & GAGTTTCTCATAGCTGGACAAT & GCATAGGTCTTGGTGAATCC \\
\hline Metallopeptidase inhibitor 2 & TIMP2 & NM_174472.4 & TGCAGACATAGTGATCAGGGCCA & AATCCGCTTGATGGGGTTGCCG \\
\hline Metallopeptidase inhibitor 3 & TIMP3 & NM_174473.4 & GCCCTTTGGCACGATGGTCT & TAGACTCGGCCTGTCACCAGGT \\
\hline Collagen 1A2 & COL1A2 & NM_174520.2 & GGATACGCGGACTTTGTTC & СTCСАCTTGGGCССТTTCT \\
\hline Collagen $3 \mathrm{~A} 1$ & COL3A1 & NM_001076831.1 & ACTGGTGCTCCTGGATTAAAG & СTTCCTCGAGCTCCATCATTAC \\
\hline Collagen 4A1 & COL4A1 & NM_001166511.1 & GGGTTCCGTAGGATTGAAAG & GAAGCСТАTСТGTCСТTTGTC \\
\hline Collagen $4 \mathrm{~A} 2$ & COLAA2 & XM_010810991.1 & CAACGGTTACGTCGAGAAG & CTTCAAGGAGACGCCTATTC \\
\hline Collagen 4A5 & COL4A5 & XM_002699860.3 & GCAGGAGAGAAAGGTAGTAAAG & ССТGСАAСТССАGGAATAC \\
\hline
\end{tabular}


Table 2 Functional enrichment of pathways related to ECM remodeling upregulated in the endometrium of SF-SCL cows ( $n=3 /$ group) on D7.

\begin{tabular}{llccc}
\hline Category & Term & Count & P $>$ F & Fold enrichment \\
\hline GOTERM_CC_FAT & Collagen & 9 & $<0.0001$ & 11.61 \\
GOTERM_CC_FAT & Fibrillar collagen & 6 & $<0.0001$ & 23.22 \\
GOTERM_MF_FAT & Extracellular matrix structural constituent & 7 & $<0.0001$ & 8.9 \\
GOTERM_BP_FAT & Collagen fibril organization & 6 & $<0.0001$ & 10.5 \\
GOTERM_MF_FAT & Growth factor binding & 6 & 0.040 & 3.14 \\
GOTERM_BP_FAT & Skin development & 3 & 0.107 & 5.28 \\
GOTERM_BP_FAT & Epidermis development & 5 & 0.134 & 2.51 \\
GOTERM_BP_FAT & Ectoderm development & 5 & 0.157 & 23.7 \\
GOTERM_BP_FAT & Blood vessel development & 6 & 0.521 & 12.5 \\
GOTERM_BP_FAT & Vasculature development & 6 & 0.544 & 1.22 \\
\hline
\end{tabular}

$P$ represents non-adjusted probabilities.

Gold; Esaote Healthcare, São Paulo, SP, Brazil) equipped with a multifrequency linear transducer. Blood samples were collected via jugular venipuncture in tubes containing heparin (BD, São Paulo, SP, Brazil) on D-1 and D4. Blood samples were immediately stored on ice after collection. To obtain plasma, blood was centrifuged at $1500 \mathrm{~g}$ for $30 \mathrm{~min}$ at $4{ }^{\circ} \mathrm{C}$. The plasma was then aliquoted and stored at $-20^{\circ} \mathrm{C}$.

On day 4 of the estrous cycle (day $0=$ injection of $\mathrm{GnRH}$ to induce ovulation), cows from LF-LCL $(n=16)$ and SF-SCL $(n=8)$ groups were stunned by a captive bolt and slaughtered by jugular exsanguination. The reproductive tract was transported on ice to the laboratory, ovarian structures were measured and weighed and the uterine horn ipsilateral to the ovary bearing the CL was incised longitudinally. Tissue from a single strip of endometrial intercaruncular region was used for each cow. Strips measured approximately $2.5 \mathrm{~cm}$ long and $5 \mathrm{~mm}$ wide and were dissected from the mid third of the horn. Samples were snap-frozen in liquid nitrogen and then transferred to $-80^{\circ} \mathrm{C}$ until processing for RNA extraction. Another portion of samples was fixed by immersion in $4 \%$ buffered formalin for $24 \mathrm{~h}$ at $4{ }^{\circ} \mathrm{C}$, followed by several washings in PBS. Subsequently, samples were embedded in Paraplast, sectioned and processed for histological analysis.

Concentrations of P4 were measured by radioimmunoassay (Coat-A-Count kit progesterone, Siemens Medical Solutions Diagnostics) validated previously for bovine plasma samples (Garbarino et al. 2004). Estradiol concentrations were measured using a commercial RIA kit (Double Antibody Estradiol, DPC, Los Angeles, CA, USA) validated previously for bovine plasma samples (Siddiqui et al. 2009). The intra-assay $\mathrm{CV}$ and sensitivity were $1.7 \%$ and $0.13 \mathrm{pg} / \mathrm{mL}$ for $\mathrm{E} 2$; and $0.8 \%$ and $0.05 \mathrm{ng} / \mathrm{mL}$ for $\mathrm{P} 4$, respectively.

\section{Study II}

Non-lactating, multiparous Nelore (Bos indicus) cows $(n=83)$ were submitted to the same hormone protocol described in Study 1 (Fig. 1) to result in the SF-SCL $(n=39)$ and LF-LCL $(n=35)$ groups. Blood collections and collection of endometrial samples were performed as previously described for Study I; exception was that endometrium harvesting was seven days post-induction of ovulation (i.e., D7). The intra-assay CV and sensitivity were $1.7 \%$ and $0.13 \mathrm{pg} / \mathrm{mL}$ for $\mathrm{E} 2$; and $0.3 \%$ and $0.076 \mathrm{ng} / \mathrm{mL}$ for $\mathrm{P} 4$ respectively. Animals within each group were ranked according to responses to the following endocrine and ovarian variables: concentration of E2 on D-1, concentration of P4 at D7, CL size at D7, CL weight at D7, follicle size at
D-2, D-1 and D0 and pre-ovulatory follicle size. The eight top ranked animals of the LF-LCL group and the nine lowest ranked animals of the SF-SCL group were chosen for transcript analysis. Likewise, the top (LF-LCL) and lowest (SF-SCL) three animals were used for RNA-seq analyses. Histological analysis for collagen was performed on samples from Experiment 1 (LF-LCL, D4 $n=4$, D7 $n=5$; SF-SCL, D4 $n=3$, D7 $n=4$ ).
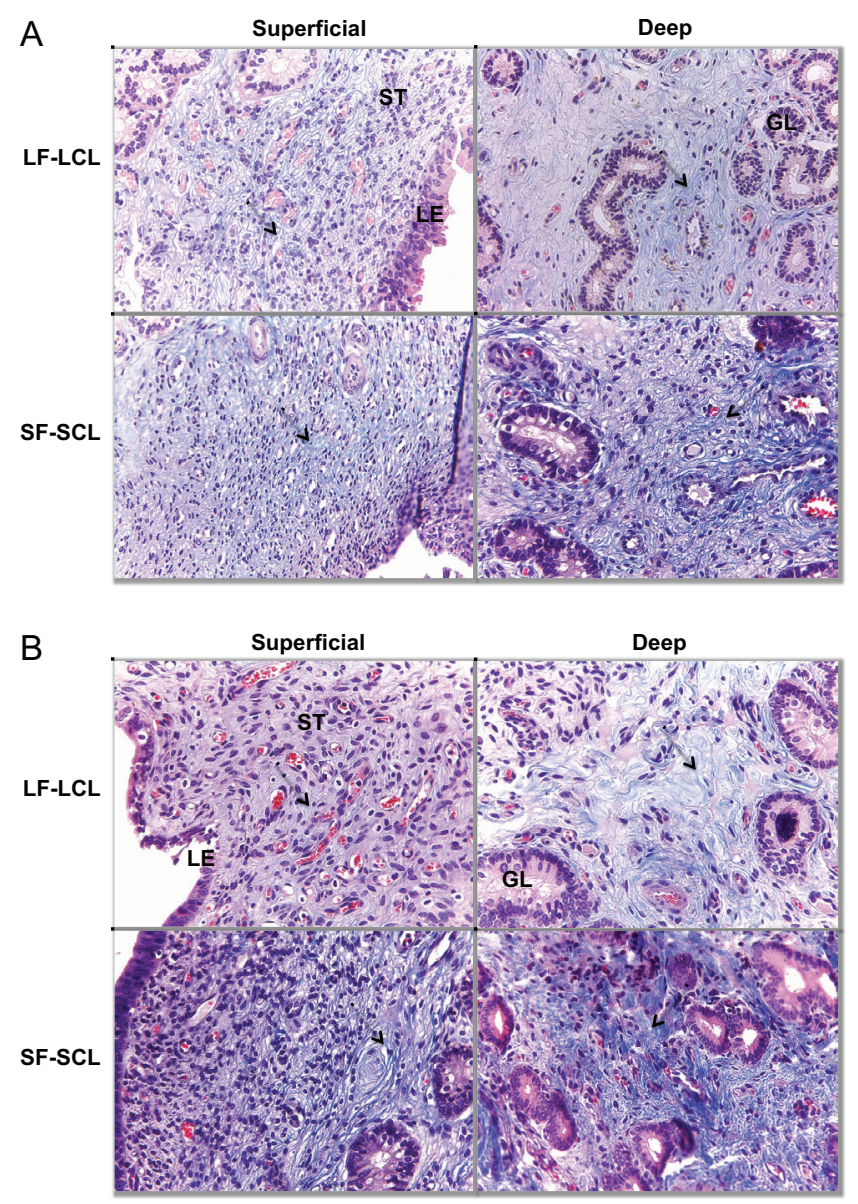

Figure 2 Collagen distribution in the endometrium of cows from SF-SCL and LF-LCL groups on D4 (A) and D7 (B). Sections were stained with Masson's trichrome stain, and images from the superficial and deep compartments of the endometrium at $40 \times$ magnification. A and B show histological sections stained with Masson's Trichrome stain. GL, gland; LE, luminal epithelium; $\mathrm{ST}$, stroma. Arrows indicate collagen content colored in blue. 
Table 3 Mean \pm SEM for collagen abundance detected by Masson's Trichrome stain on days 4 ( $n=3-5 /$ group) and 7 ( $n=4-5 /$ group) of the estrous cycle from the superficial and deep compartments of the endometrium from cows from the Small Follicle-Small Corpus Luteum group (SF-SCL) and Large Follicle-Large Corpus Luteum group (LF-LCL).

\begin{tabular}{|c|c|c|c|c|c|c|c|}
\hline \multirow[b]{2}{*}{ End point } & \multicolumn{2}{|c|}{ SF-SCL } & \multicolumn{2}{|c|}{ LF-LCL } & \multicolumn{3}{|c|}{$P>F$} \\
\hline & Superficial & Deep & Superficial & Deep & Group & Region & $\mathrm{G} \times \mathrm{R}^{\mathrm{a}}$ \\
\hline $\begin{array}{l}\text { Collagen abundance } \\
\text { on Day } 4(\%)\end{array}$ & $35.4 \pm 1.7$ & $40.9 \pm 4.7$ & $31.9 \pm 2.9$ & $37.7 \pm 2.0$ & 0.016 & 0.007 & 0.940 \\
\hline $\begin{array}{l}\text { Collagen abundance } \\
\text { on Day } 7(\%)\end{array}$ & $36.0 \pm 3.0$ & $40.8 \pm 1.4$ & $35.1 \pm 4.1$ & $38.8 \pm 3.7$ & 0.755 & 0.045 & 0.768 \\
\hline
\end{tabular}

${ }^{\mathrm{a}} \mathrm{G} \times \mathrm{R}=$ interaction between group and region.

\section{Experiment 2. Reproductive management and experimental design}

As described previously by Binelli and coworkers (2015), cows were synchronized $(n=51)$ to estrus by injecting two i.m. doses of PGF2 $\alpha$ analogue ( $0.5 \mathrm{mg}$ sodium cloprostenol; Sincrocio) 14 days apart. At the time of the second PGF2 $\alpha$ injection, animals were equipped with an Estrotect Heat detector patch (Rockway, Inc.) device and were observed twice daily for six days for estrous behavior. Ultrasound exams were performed $12 \mathrm{~h}$ after estrus to confirm the presence and location of a POF. Artificial insemination (AI) was performed in all cows that showed estrous signs $(n=33)$ with cryopreserved semen from a single ejaculate. Six days after $\mathrm{Al}$, an endometrial biopsy $(\sim 50 \mathrm{mg})$ was collected from the caudal third of the uterine horn contralateral to the ovary containing a $\mathrm{CL}$ and stored at $-80^{\circ} \mathrm{C}$. After the biopsy procedure, cows received two $1 \mathrm{~g}$ doses of the antiinflammatory medication flunixin meglumine (Desflan, Ourofino) in a 24-h interval and one dose of penicillin/ streptomycin base antibiotic (Penfort Reforçado, Ourofino). A blood sample was collected, and plasma P4 concentrations were measured as described for Experiment 1. Pregnancy diagnosis was performed on day 30 after Al via transrectal ultrasonography exam. RNA-Seq was performed on samples selected retrospectively based on the day 30 pregnancy diagnosis using six samples from each pregnant $(\mathrm{P})$ and non-pregnant (NP) animals. Animals were selected based on plasma progesterone concentrations on day 6 , that must had been within a $1.5 \mathrm{ng} / \mathrm{mL}$ interval among all animals. Abundance of specific transcripts was quantified by qPCR in ten $\mathrm{P}$ and sixteen NP randomly selected animals.

\section{RNA isolation and CDNA synthesis}

Endometrial tissue samples (approximately $30 \mathrm{mg}$ ) were snap frozen in liquid nitrogen, macerated in a stainless steel apparatus and immediately mixed with buffer RLT from the RNeasy Mini columns kit (Qiagen), to be processed according to the manufacturer's instructions. To maximize cell lysis, tissue suspension was passed at least ten times through a $21 \mathrm{G}$ needle, and centrifuged at $13,000 \mathrm{~g}$ for $3 \mathrm{~min}$ for removal of debris, prior to supernatant loading and processing in RNeasy columns. Columns were eluted with $40 \mu \mathrm{L}$ of Rnase-free water, and elution was repeated using the same $40 \mu \mathrm{L}$ initially used to increase RNA concentration. Concentration and purity of total RNA were estimated using a spectrophotometer (NanoDrop, Thermo Fisher Scientific).
RNA integrity and quantity were assessed by Bioanalyzer (Agilent Technologies Brazil Ltda), and only samples with RNA integrity number (RIN) greater than 7 were processed further. Total RNA extracts were stored at $-80^{\circ} \mathrm{C}$ until subsequent analysis. Immediately prior to cDNA synthesis, samples were treated with DNAse I (Life Technologies) at room temperature for $15 \mathrm{~min}$. DNase I activity was blocked using EDTA solution $(25 \mathrm{mM})$ and heating at $65^{\circ} \mathrm{C}$ for $10 \mathrm{~min}$. Reverse transcription was performed immediately after DNAse I treatment using High-Capacity cDNA Reverse Transcription Kit (Life Technologies), according to manufacturer's instructions. Briefly, $9 \mu \mathrm{L}$ of master mix containing reverse transcription buffer, deoxyribonucleotide triphosphate mix, random primers, RNase inhibitor and reverse transcriptase were added to the $11 \mu \mathrm{L}$ DNase I treatment reaction. Immediately, samples were incubated at $25^{\circ} \mathrm{C}$ for $10 \mathrm{~min}$, followed by incubation at $37^{\circ} \mathrm{C}$ for $2 \mathrm{~h}$ and reverse transcriptase inactivation at $85^{\circ} \mathrm{C}$ for $5 \mathrm{~min}$ and storage at $20^{\circ} \mathrm{C}$.

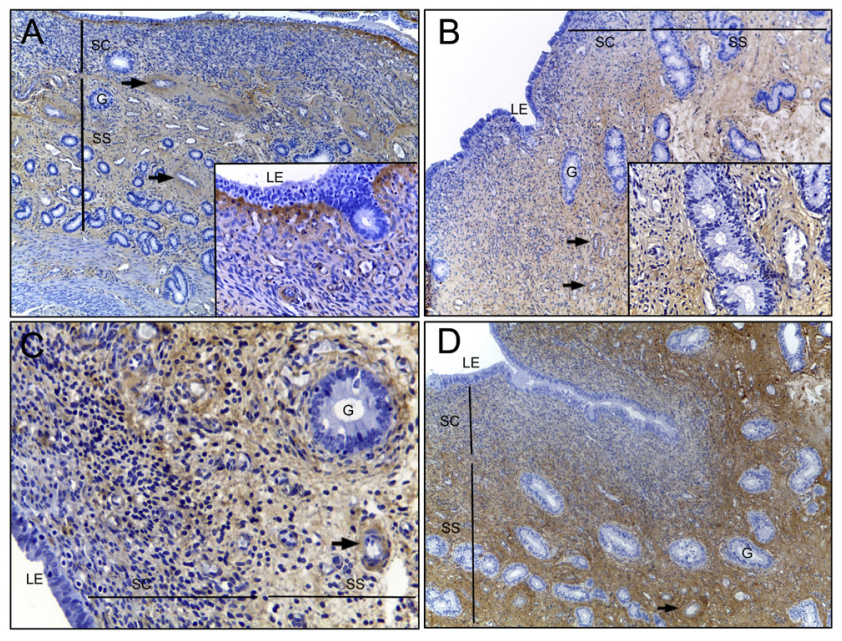

Figure 3 Collagen type I distribution in the endometrium of cows from SF-SCL (A and B) and LF-LCL (C and D) groups on D4 and D7 respectively. Collagen type $\mathrm{I}$ is scarce in the stratum compactum (SC) and found predominantly within the stratum spongiosum (SS) in both groups, around endometrial glands (G) and blood vessels (arrows). (A) In the SF-SCL group, a dense sub-epithelial mesh was observed on day 4 (A, inset), but not on day 7 , in which larger amounts and thicker fibers of collagen I were found in the stratum spongiosum ( $B$, inset). IHC, counterstained with Harris' hematoxylin. (LE, luminal epithelium; A, B and D: $10 \times$ objective; C and insets: $40 \times$ objective). 


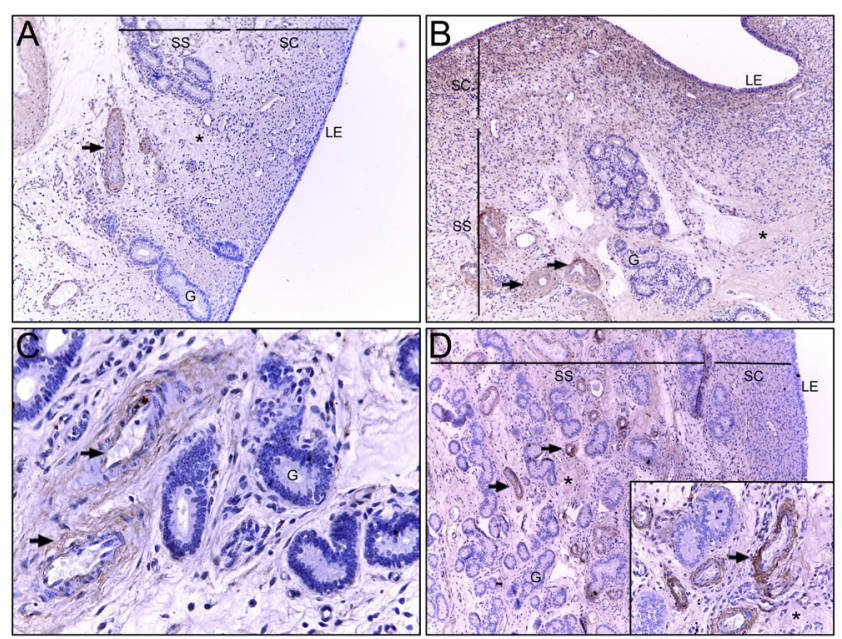

Figure 4 Collagen type III distribution in the endometrium of cows from SF-SCL (A and B) and LF-LCL (C and D) groups on D4 and D7 respectively. Collagen type III is present in both the stratum compactum (SC) and stratum spongiosum (SS) in low quantities, as thin fibers in the interstitium (asterisk) and predominantly around blood vessels (arrows). IHC, counterstained with Harris' hematoxylin. (G, endometrial glands; LE, luminal epithelium; A, B and D: 10× objective; $\mathrm{C}$ and inset: $40 \times$ objective).

\section{mRNA libraries, sequencing and bioinformatics}

Methods and general results from transcriptomic analysis of tissues from Experiments 1 and 2 were published previously (Binelli et al. 2015, Mesquita et al. 2015). Briefly, cDNA was generated using a routine RNA library preparation TruSeq protocol developed by Illumina Technologies (San Diego, CA, USA) using $4 \mu \mathrm{g}$ of total RNA as input. Preparation involved mRNA isolation from total RNA by a polyA selection step, followed by construction of paired-end sequencing libraries with an insert size of 300 bp. Briefly, mRNA was selected by oligo-dT magnetic beads and fragmented into small pieces using divalent cations. Cleaved mRNA fragments were copied into first-strand cDNA using reverse transcriptase and random primers, which was followed by second-strand cDNA synthesis using DNA polymerase I. The cDNA fragments then underwent an end repair process, the addition of a single $\mathrm{A}$ base, and then ligation of the adapters. Resulting products were amplified via PCR and CDNA libraries were then purified and validated using the Bioanalyzer 2100 (Agilent Technologies). Paired-end sequencing was performed using the Illumina HiScanSq 2000 platform. The paired end (PE) reads were filtered using the package Seqyclean v1.4.13, (https://bitbucket.org/izhbannikov/ seqyclean). The reads were mapped using the local alignment with Bowtie2 against the masked Bos taurus genome assembly (Bos Taurus UMD3.1). The mapping file was sorted using SAMTools $\vee 0.1 .18$, and read counts were obtained using HTSeq-count v0.5.4p2 (http://www-huber.embl.de/users/ anders/HTSeq/doc/count.html). The differential expression analysis was performed with package DESEq v1.12.1 (Andres \& Huber 2010), from R (Gentleman et al. 2004) for samples of Experiment 1. For samples of Experiment 2, the differential expression analysis was performed with package DESEq2 v1.12.1 (Love et al. 2014) from R (Gentleman et al. 2004). The standard deviation along the baseMean values was also calculated for each transcript. To avoid artifacts caused by low expression profiles and high expression variance, only transcripts that had an average of baseMean $>5$, and the mean greater than the standard variation were analyzed. The threshold for evaluating significance was obtained by applying a $P$ value of 0.05 FDR-Benjamini-Hochber (Benjamini \& Hochber 1995). Integrated analysis of different functional databases was done using the functional annotation tool of the Database for Annotation, Visualization, and Integrated Discovery (DAVID Bioinformatics Resources 6.7, NIAID/NIH) using as background the transcribed genes found (Dennis et al. 2003).

\section{Design and validation of primers and quantitative real-time $P C R$}

Quantitative PCR reactions were performed using the StepOnePlus apparatus (Life Technologies). Primer sequences were either obtained from the literature or designed by Primer Express software V.3.0.1 (Life Technologies) (Table 1). Each newly designed primer pair was selected based on the Gibbs free energy $(\Delta G)$ values for hairpin, homodimers and heterodimers formation indicated by the Oligo Analyzer 3.1 software (IDT; http://www.idtdna.com/analyzer/Applications/

Table 4 Functional enrichment of pathways related to ECM remodeling upregulated in the endometrium of NP cows ( $n=5-6$ cows/group) on D6.

\begin{tabular}{llrrr}
\hline Category & Term & Count & P $>\boldsymbol{F}$ & Fold enrichment \\
\hline GOTERM_CC_FAT & Proteinaceous extracellular matrix & 14 & $<0.0001$ & 77.7 \\
GOTERM_CC_FAT & Extracellular region & 30 & $<0.0001$ & 3.0 \\
GOTERM_CC_FAT & Extracellular matrix & 14 & $<0.0001$ & 7.1 \\
GOTERM_CC_FAT & Basement membrane & 8 & $<0.0001$ & 20.1 \\
GOTERM_CC_FAT & Extracellular matrix part & 9 & $<0.0001$ & 14.8 \\
GOTERM_CC_FAT & Extracellular region part & 19 & $<0.0001$ & 4.0 \\
GOTERM_CC_FAT & Basement membrane & 8 & $<0.0001$ & 14.1 \\
GOTERM_CC_FAT & Extracellular matrix part & 9 & $<0.0001$ & 839.5 \\
GOTERM_BP_FAT & Extracellular structure organization & 6 & $<0.0001$ & 896.0 \\
GOTERM_BP_FAT & Extracellular matrix organization & 5 & 0.002 & 8.1 \\
GOTERM_BP_FAT & Regulation of cell adhesion & 5 & 0.003 & 16.1 \\
GOTERM_BP_FAT & Positive regulation of cell-substrate adhesion & 3 & 0.014 & \\
GOTERM_BP_FAT & Regulation of cell-substrate adhesion & 3 & 0.029 & \\
GOTERM_BP_FAT & Positive regulation of cell adhesion & 3 & 0.035 & \\
\hline
\end{tabular}

$P>F$ represents non-adjusted probabilities. 
Table 5 Validation of RNAseq ( $n=3$ cows/group) gene expression data by qPCR ( $n=8-9$ cows/group). Fold change and probability value $(P>F)$ of gene expression in SF-SCL vs LF-LCL uterine samples on D7.

\begin{tabular}{|c|c|c|c|c|c|c|c|}
\hline \multirow[b]{2}{*}{ Ensembl Id } & \multirow[b]{2}{*}{ Gene symbol } & \multicolumn{3}{|c|}{ RNAseq } & \multicolumn{3}{|c|}{ qPCR } \\
\hline & & Fold change & log2 fold change & $P>F$ & Fold change & log2 fold change & $P>F$ \\
\hline ENSBTAG00000020457 & TGFB1 & 1.25 & 0.32 & 0.627 & 2.05 & 1.04 & 0.551 \\
\hline ENSBTAG00000005359 & TGFB2 & 1.77 & 0.82 & 0.053 & 1.86 & 0.90 & 0.043 \\
\hline ENSBTAG00000012004 & TGFB3 & 1.23 & 0.30 & 0.932 & 1.43 & 0.52 & 0.487 \\
\hline ENSBTAG00000005043 & TIMP1 & 1.49 & 0.57 & 0.018 & 2.04 & 1.03 & 0.043 \\
\hline ENSBTAG00000010899 & TIMP2 & 0.86 & -0.22 & 0.369 & 0.92 & -0.12 & 0.326 \\
\hline ENSBTAG00000020638 & TIMP3 & 0.68 & -0.55 & 0.032 & 0.59 & -0.76 & 0.019 \\
\hline ENSBTAG00000019267 & $M M P 2$ & 1.37 & 0.46 & 0.240 & 1.22 & 0.29 & 0.277 \\
\hline ENSBTAG00000014824 & MMP14 & 1.44 & 0.53 & 0.134 & 1.38 & 0.46 & 0.215 \\
\hline ENSBTAG00000014665 & ADAMTS2 & 1.46 & 0.55 & 0.054 & 1.53 & 0.61 & 0.042 \\
\hline ENSBTAG00000000648 & ADAMTS5 & 1.71 & 0.77 & 0.000 & 1.24 & 0.31 & 0.003 \\
\hline ENSBTAG00000013103 & COL1A1 & 1.50 & 0.58 & 0.058 & 1.80 & 0.85 & 0.046 \\
\hline ENSBTAG00000013472 & COL1A2 & 1.56 & 0.64 & 0.001 & 1.87 & 0.90 & 0.014 \\
\hline ENSBTAG00000021466 & COL3A1 & 1.62 & 0.70 & 0.000 & 1.32 & 0.40 & 0.002 \\
\hline ENSBTAG00000012849 & COL4A1 & 1.38 & 0.46 & 0.032 & 1.92 & 0.94 & 0.023 \\
\hline ENSBTAG00000014575 & COL4A5 & 0.64 & -0.65 & 0.027 & 0.75 & -0.42 & 0.021 \\
\hline
\end{tabular}

OligoAnalyzer/). Primers were subsequently checked for specificity using the Basic Local Alignment Search Tool (Blast; http://blast.ncbi.nlm.nih.gov/Blast.cgi).

Selected primer pairs were evaluated to determine the optimal primer concentration by using a pool of endometrial cDNA, at a 1:80 dilution. Each primer pair was tested in reactions prepared with the following primer concentrations: 150,300 or $600 \mathrm{nM}$. Optimal primer concentrations were determined based on the lowest primer concentration that obtained amplification efficiency between $85 \%$ and $100 \%$, presented a single amplification peak and had no peaks detected on the negative control reactions, in the dissociation curve, and generated the lowest cycle quantification (Cq) value. Additionally, the standard curve amplification efficiency was determined based on a standard curve, generated by a serially diluted cDNA pool with at least 5 dilutions. Acceptable standard curve efficiencies were between $83 \%$ and $100 \%$ and $r^{2}$ close to 1 .

Relative abundance of specific transcripts between LF-LCL and SF-SCL samples (Experiment 1) and pregnant and nonpregnant samples (Experiment 2 ) was assessed by $20 \mu \mathrm{L}$ reactions in a 96-well plate, sealed with MicroAmp optical adhesive cover (Life Technologies), in triplicates. Raw fluorescence data were extracted from the StepOne Plus apparatus with no baseline correction and submitted to LinRegPCR software for baseline correction, determination of PCR efficiency and cycle quantification $(\mathrm{Cq})$ values per sample. $\mathrm{Cq}$ values were obtained from the LinReg PCR software. The log-linear portion of the amplification curve used for analysis on LinReg PCR software contained from four to six points with the highest $R^{2}$ value. Relative quantification for all tested genes was processed according to the $\Delta \Delta \mathrm{Ct}$ method, using cyclophilin as a reference gene. Identity of each PCR amplification product was confirmed by sequencing.

\section{Masson's trichrome staining}

Paraplast embedded tissues were sectioned $(4 \mu \mathrm{m})$. Three histological sections from each animal were deparaffinized in xylene, rehydrated through a graded series of ethanol
$(100 \%, 95 \%$ and $70 \%$ ), rinsed in running tap water for $10 \mathrm{~min}$ and a final rinse in distilled water. Tissues were stained in Weigert's iron hematoxylin working solution for $10 \mathrm{~min}$, rinsed in running tap water for $10 \mathrm{~min}$ and in distilled water. Then tissues were stained in Biebrich scarlet-acid fuchsine solution for $15 \mathrm{~min}$ and washed in distilled water placed in phosphomolybdic-phosphotungstic acid solution for $10 \mathrm{~min}$ and transferred directly (without rinse) to aniline blue solution and stained for $15 \mathrm{~min}$. Next, tissues were washed in running tap water and rinsed briefly in distilled water, and then immersed in 1\% acetic acid solution for $3 \mathrm{~min}$. The tissues were washed in distilled water, dehydrated very quickly through 95\% ethyl alcohol, absolute ethyl alcohol and cleared in xylene. Finally, tissues were mounted under a coverslip. From each section, ten random high-power fields $(40 \times$ objective) were digitized: five that were adjacent to the uterine lumen (denominated superficial glandular epithelium) and five that were adjacent to myometrium. This method was chosen to avoid superimposing of photomicrographs and, thus, to separate deep from superficial areas. Staining was analyzed using Imagej software (U.S. National Institutes of Health, Bethesda, Maryland, USA). The area and corresponding pixels represented by a range of the color blue, representing collagen content was calculated and represented as percentage for the superficial and deep compartments of the endometrium. The samples were analyzed by a single pathologist, who was blinded to information about the animals. The final value was calculated as the average of five different evaluated fields in each compartment, for each tissue section.

\section{Immunohistochemistry for collagens type I and III}

Four cows were selected from each group on D4 and D7 for immunohistochemical analyses of collagen tissue distribution. From each cow, histological sections $(4 \mu \mathrm{m})$ were deparaffinized, rehydrated and subjected to enzymatic digestion with $0.4 \%$ pepsin (Sigma) diluted in $0.5 \mathrm{~N}$ acetic acid for $30 \mathrm{~min}$ at $37^{\circ} \mathrm{C}$. After blocking endogenous peroxidase with $6 \% \mathrm{H}_{2} \mathrm{O}_{2}$ solution (Merck) for $30 \mathrm{~min}$, the slides were incubated in a humidified chamber overnight at $4^{\circ} \mathrm{C}$ with the 
Table 6 Validation of RNAseq ( $n=5-6$ cows/group) gene expression data by qPCR ( $n=10-16$ cows/group). Fold change and probability value $(P>F)$ of gene expression in uterine biopsies from non-pregnant vs pregnant animals.

\begin{tabular}{|c|c|c|c|c|c|c|c|}
\hline \multirow[b]{2}{*}{ Ensembl Id } & \multirow[b]{2}{*}{ Gene symbol } & \multicolumn{3}{|c|}{ RNAseq } & \multicolumn{3}{|c|}{ qPCR } \\
\hline & & Fold change & log2 fold change & $P>F$ & Fold change & log2 fold change & $P>F$ \\
\hline ENSBTAG00000020457 & TGFB1 & 1.46 & 0.55 & 0.018 & 1.23 & 0.30 & 0.051 \\
\hline ENSBTAG00000005359 & TGFB2 & 0.73 & -0.46 & 0.016 & 1.20 & 0.26 & 0.032 \\
\hline ENSBTAG00000005043 & TIMP1 & 0.87 & -0.20 & 0.018 & 2.04 & 1.03 & 0.043 \\
\hline ENSBTAG00000010899 & TIMP2 & 1.01 & 0.01 & 0.369 & 0.92 & -0.12 & 0.326 \\
\hline ENSBTAG00000020638 & TIMP3 & 1.40 & 0.49 & 0.033 & 0.59 & -0.76 & 0.019 \\
\hline ENSBTAG00000019267 & $M M P 2$ & 1.56 & 0.64 & 0.240 & 1.22 & 0.29 & 0.277 \\
\hline ENSBTAG00000014824 & MMP14 & 1.46 & 0.54 & 0.134 & 1.38 & 0.46 & 0.215 \\
\hline ENSBTAG00000000706 & ADAMTS1 & 1.66 & 0.73 & 0.001 & 1.21 & 0.27 & 0.003 \\
\hline ENSBTAG00000014665 & ADAMTS2 & 1.56 & 0.64 & 0.005 & 1.22 & 0.29 & 0.000 \\
\hline ENSBTAG00000013210 & ADAMTS4 & 1.62 & 0.69 & 0.013 & 0.99 & -0.01 & 0.230 \\
\hline ENSBTAG00000000648 & ADAMTS5 & 1.37 & 0.45 & 0.083 & 1.22 & 0.29 & 0.055 \\
\hline ENSBTAG00000013472 & COL1A2 & 1.40 & 0.49 & 0.050 & 1.49 & 0.57 & 0.033 \\
\hline ENSBTAG00000021466 & COL3A1 & 1.44 & 0.52 & 0.041 & 1.22 & 0.29 & 0.023 \\
\hline
\end{tabular}

following rabbit primary antibodies: collagen type I (\#600401-103, Rockland, USA; 1:3000) or collagen type III (\#600401-105, Rockland, USA; 1:5000). The slides were then incubated with the complex Super Picture Polymer Detection kit (Life Technologies) for $30 \mathrm{~min}$ at $37^{\circ} \mathrm{C}$. The reaction was visualized with 3'3 diaminobenzidine chromogen and counterstained with Harris hematoxylin. The negative controls were performed replacing the primary antibodies with normal rabbit IgG (\#sc-2027, Santa Cruz Biotechnology). Sections were finally observed by light microscopy using the $10 \times$ or the $40 \times$ objectives. One representative image from each group on each of days 4 or 7 was selected for visualization.

\section{Statistical analyses}

The data were tested for normality of residues using ShapiroWilk test. Data that were not normal were transformed by log10. Ovarian, endocrine and transcript abundance variables were analyzed by one-way ANOVA to test the effect of group (LF-LCL vs SF-SCL) using the PROC GLM procedure of the SAS software (Version 9.2; SAS Institute). Histology data were analyzed by two-way ANOVA to test the effect of group, region (superficial or deep compartments of the endometrium) and the interaction.

\section{Results}

\section{Experiment 1: Influence of peri-ovulatory hormonal modulation on endometrial ECM remodeling characteristics on day 7 of the estrous cycle}

\section{Animal model}

Results from the animal model used here were reported previously (Mesquita et al. 2015). Briefly, in Study I, follicle diameter on D-1, plasma concentration of E2 on D-1, CL area on D4 and plasma concentration of P4 on D4 were 38.81, 275.54, 65.68 and 75\% greater for the LF-LCL compared to the SF-SCL group, respectively $(P<0.01)$. Similarly, in Study II, follicle diameter on D0, plasma concentration of E2 on D-1, CL volume on D7 and plasma concentration of P4 on D7 were 23.99 $(P<0.01), 360(P<0.01), 61.67(P<0.04)$ and $47.79 \%$
$(P<0.04)$ greater for the LF-LCL compared to the SF-SCL group, respectively.

\section{ECM-related gene expression}

A comprehensive analysis of the RNA-seq data of Experiment 1 was reported previously (Mesquita et al. 2015). Briefly, the analysis of day 7 endometrial LF-LCL vs SF-SCL samples yielded a total of approximately 134 million reads and approximately $62 \%$ of the total reads uniquely mapped to the UMD 3.1 reference genome (http://www.ncbi.nlm.nih.gov/genome/guide/ cow/index.html). After applying the filter for variance and minimal value of baseMean, a total of 562 genes showed differential expression (adjusted $P$ value $<0.1$ ), of which 364 and 198 were upregulated in the endometrium of LF-LCL and SF-SCL animals, respectively. Functional enrichment analysis for the SF-SCL endometrial tissue revealed clusters with overrepresented ontology terms and activation of pathways associated with extracellular matrix region and organization (Table 2).

\section{Histological and immunohistochemical evaluation of collagen content and tissue distribution}

The Masson's trichrome staining method was used to determine the abundance of total collagen in the endometrium. There was increased collagen content in the low-receptivity SF-SCL group on day $4(P=0.02$; Fig. 2 and Table 3). On days 4 and 7 , a greater abundance of collagen was observed in the deep compartment compared to the superficial in both treatment groups $(P<0.05)$.

Immunohistochemistry analyses were performed to indicate cell-specific distribution of collagens I and III (Figs 3 and 4, respectively) in the endometrium. There were gradients of staining among animals and, sometimes, within a same animal. Collagen type I was scarce in the stratum compactum and found predominantly within the stratum spongiosum, in both groups. It appeared as thicker fibers around endometrial glands and blood vessels (Fig. 3). In the SF-SCL group, a 
Table 7 ECM-related genes detected in the RNAseq data comparing cows with distinct peri-ovulatory milieus (SF-SCL vs LF-LCL; $n=3$ Cows/ group) and pregnancy status (NP vs $\mathrm{P} ; n=5-6$ cows/group). Fold changes were the ratio of the mean expression values of SF-SCL/LF-LCL and NP/P.

\begin{tabular}{|c|c|c|c|c|c|c|c|}
\hline \multirow[b]{2}{*}{ Ensembl Id } & \multirow[b]{2}{*}{ Gene symbol } & \multicolumn{3}{|c|}{ SF-SCL vs LF-LCL } & \multicolumn{3}{|c|}{ NP vs P } \\
\hline & & Fold change & log2 fold change & $P>F$ & Fold change & log2 fold change & $P>F$ \\
\hline ENSBTAG00000020457 & TGFB 1 & 1.25 & 0.32 & 0.627 & 1.46 & 0.55 & 0.018 \\
\hline ENSBTAG00000005359 & TGFB2 & 1.77 & 0.82 & 0.053 & 0.73 & -0.46 & 0.016 \\
\hline ENSBTAG00000012004 & TGFB3 & 1.23 & 0.30 & 0.932 & 1.03 & 0.04 & 0.870 \\
\hline ENSBTAG00000005043 & TIMP1 & 1.49 & 0.57 & 0.018 & 0.87 & -0.20 & 0.018 \\
\hline ENSBTAG00000010899 & TIMP2 & 0.86 & -0.22 & 0.369 & 1.01 & 0.01 & 0.369 \\
\hline ENSBTAG00000020638 & TIMP3 & 0.68 & -0.55 & 0.032 & 1.40 & 0.49 & 0.033 \\
\hline ENSBTAG00000019267 & $M M P 2$ & 1.37 & 0.46 & 0.240 & 1.56 & 0.64 & 0.240 \\
\hline ENSBTAG00000014824 & MMP14 & 1.44 & 0.53 & 0.134 & 1.46 & 0.54 & 0.134 \\
\hline ENSBTAG00000014665 & ADAMTS2 & 1.46 & 0.55 & 0.054 & 1.56 & 0.64 & 0.005 \\
\hline ENSBTAG00000000648 & ADAMTS5 & 1.71 & 0.77 & 0.000 & 1.37 & 0.45 & 0.083 \\
\hline ENSBTAG00000013103 & COL1A1 & 1.5 & 0.58 & 0.058 & 1.07 & 0.10 & 0.745 \\
\hline ENSBTAG00000013472 & COL1A2 & 1.56 & 0.64 & 0.001 & 1.40 & 0.49 & 0.050 \\
\hline ENSBTAG00000021466 & COL3A1 & 1.62 & 0.70 & 0.000 & 1.44 & 0.52 & 0.041 \\
\hline ENSBTAG00000012849 & COL4A1 & 1.38 & 0.46 & 0.032 & 1.19 & 0.26 & 0.274 \\
\hline ENSBTAG00000014575 & COL4A5 & 0.64 & -0.65 & 0.027 & - & _- & _- \\
\hline
\end{tabular}

dense sub-epithelial mesh was observed on day 4 , but not on day 7 , in which larger amounts of collagen I were found in the stratum spongiosum. Collagen type-III had ubiquitous distribution (Fig. 4). It was found in both the stratum compactum and stratum spongiosum, in lower quantities than collagen type I. The fibers were thin, homogeneously distributed in the interstitium, mainly around blood vessels.

\section{Experiment 2 - ECM remodeling in endometrial biopsies collected 6 days after Al and its relation to pregnancy success}

\section{Animal model}

Results from the animal model used here were reported previously (Binelli et al. 2015). A total of 51 cows were synchronized and 33 displayed estrus, ovulated and hence, received $\mathrm{Al}$. Cows showing P4 concentrations on day 6 after Al between 4.3 and $5.8 \mathrm{ng} / \mathrm{mL}$ were selected for RNA sequencing $\mathrm{P}(n=6)$ and NP $(n=6)$.

\section{ECM-related gene expression}

A comprehensive analysis of the RNA-seq data of Experiment 2 was reported previously (Binelli et al. 2015). Briefly, endometrial ECM-related gene expression levels in P vs NP day 6 endometrial tissue $\mathrm{P}$ and NP samples were analyzed in an Illumina single flow cell line. The 272,685,768 million filtered reads were mapped to the Bos taurus UMD3.1 reference genome, and 14,654 genes were effectively analyzed for differential expression between groups. From six biopsies collected in the NP cows, one sample did not align with the bovine genome and was omitted from the analysis. Transcriptome data showed that 216 genes were differently expressed when comparing $P$ vs NP endometrial tissue $\left(P_{\text {adj }}<0.1\right)$. More specifically, 36 genes showed a significantly upregulated expression for pregnant cows and 180 were upregulated for nonpregnant cows. Functional annotation clustering for the NP group revealed most significantly enriched pathways also associated with ECM remodeling (Table 4).

\section{Experiments 1 and 2. Overlapping ECM-related gene expression}

The RNA-seq data suggest that most enriched pathways in the SF-SCL and NP groups play a relevant role in endometrial extracellular matrix remodeling. Therefore, we focused on the expression of such genes and used quantitative real-time PCR (qRT-PCR) to compare samples from LF-LCL and SF-SCL animals on day 7 of the estrous cycle to detect changes due to a distinct peri-ovulatory endocrine milieu (Table 5). The same was done for samples from $\mathrm{P}$ and NP animals (Table 6). The mRNA expression of TGF $\beta 1$ was increased in the NP group and TGF $\beta 2$ was increased in both NP as well as in the SF-SCL group on day 7 . A similar mRNA expression pattern was observed for MMP2, MMP11 and MMP14 for the NP group. As metalloproteinase inhibitors are a crucial factor to control MMP activity in endometrial ECM remodeling in humans (Irwin et al. 2001), we investigated their mRNA expression. TIMP1 and TIMP4 expression significantly increased in the SF-SCL and NP groups respectively, whereas TIMP3 was highly expressed in both SF-SCL and NP groups.

Expression of TIMP2 was neither influenced by steroid hormone levels nor the animal's receptivity status. A significant increase $(P<0.05)$ in several ADAM and ADAMTS mRNA expression level was observed in both SF-SCL and NP groups. In both experiments, the expression of mRNA was increased for several collagens including collagen type I (COL1A2), collagen type III (COL3A1), collagen type VII (COL7A1) and collagen type IX (COL9A3), although other types of collagens were independently overexpressed in each individual 
experiment (Table 7). According to the gene ontological classification, such collagens, especially COL1A1, COL1A2, COL3A1, COL4A1 and COL4A2 are essentially involved in ECM receptor interaction pathway and structure organization, and hence, remodeling.

\section{Discussion}

Peri-ovulatory regulation of mice and human endometrial tissue remodeling has been considered a prerequisite for proper maternal receptivity. In comparison with the latter species, cows are expected to exhibit a much more limited degree of tissue remodeling during the reproductive cycle. However, recent studies identified ECM remodeling pathways as potential key for acquisition of maternal receptivity (Mesquita et al. 2015) and pregnancy success (Binelli et al. 2015). However, in cattle, clear insights in how, and to which extent, the ECM remodeling events are being regulated during early diestrus are lacking. Therefore, this study focused on the characterization of the ECM signature of the bovine endometrial tissue during early diestrus.

The first set of experiments revealed that specific peri-ovulatory endocrine profiles do impact on the ECM-related transcriptome signature of day 7 endometrial tissue. More specifically, higher mRNA levels for MMP2, COL1A2 and TIMP1, that are genes encoding molecules involved in ECM remodeling processes, were observed in the SF-SCL endometrial tissue compared with the LF-LCL counterparts. The process of extracellular matrix remodeling is a dynamic process that requires the degradation of its components. In this context, collagenases, such as the MMPs, are considered as key mediators triggering degradation of the main ECM components (Nagase et al. 2006). More specifically, collagenases (MMP$1,-8$, and -13) cleave the interstitial collagens I, II and III. The denatured collagen, or gelatin, is further degraded by gelatinases (MMP-2, and -9) (Snoek et al. 2005, Sluijter et al. 2006). Interestingly, based on the temporal fluctuations in collagen abundance between day 4 (SF-SCL $>$ LF-LCL) and day 7 (SF-SCL LF-LCL) endometrial tissue, a clear switch in sex steroid-mediated ECM remodeling activity can be reported during early diestrus. Thereby, the data seem to confirm that a physiological reorganization of the ECM during diestrus is required to promote a receptive endometrial state. Salilew-Wondim and coworkers (2010) also confirmed a higher expression of COL1A1, COL1A2 and COL27A1 in cows with a lower receptivity as seen in our animals with SF-SCL. Moreover, a study performed in cows revealed that genes related to ECM remodeling are more abundant at estrus, whereas at diestrus, the more prominent genes are related to immune response and metabolic pathways (Mitko et al. 2008).
Besides the gene expression data pointing to ECM remodeling events at transcriptome level, colorimetric assessments were used to evaluate potential phenotypic differences in endometrial ECM remodeling. Overall, the collagen visualization revealed a greater abundance of total collagen content in the SF-SCL group on day 4 , but not at day 7 . Remarkably, on day 4, pre-ovulatory follicle size appeared to have a greater influence on differences in collagen abundance in both epithelia, compared to data retrieved on day 7 . At the latter timing, only a regional difference in collagen abundance was noted, being greater in the deep endometrial compartment (i.e., stratum spongiosum) compared to the superficial (i.e., stratum compactum). Such finding was consistent with the immunoreactive abundance of collagen I (Fig. 3). Main patterns of collagen I distribution were similar to the previous descriptions by Boos (2000). For example, a sub-epithelial felt was described by that author and also clearly visible in Fig. 3 (panel A). Regarding collagen III (Fig. 4), it was clearly associated with blood vessels and capillaries, which is also consistent with descriptions by Boos (2000). That author reported changes in distribution of both collagens I and III in the uterine wall across the estrous cycle. He suggested that the cycle dependent, sex steroid concentration changes probably regulate the abundance and distribution of these and other collagens. This concept is consistent with our gene expression data for Experiment 1, in that hormonal differences associated with each experimental group were associated with different patterns of ECM-related transcript abundance.

The bovine data documented in the present study match with human data available, represented by similar differences in ECM transcripts, as well as effective collagen abundance, when comparing receptive vs low-receptive endometrial samples during early diestrus (Jokimaa et al. 2002). Data from human studies also showed previously that hormonal profiles modulate changes in the ECM's composition and distribution (Marbaix et al. 1992, Rodgers et al. 1994, Curry \& Kevin 2001). During the process of decidualization, the expression of MMPs is inhibited and TIMPs are stimulated; hence, endometrial MMP expression appears to be negatively regulated by P4. Expression of MMPs is suppressed during the secretory phase of the cycle and increased at menstruation (Osteen et al. 1999). In this context, women with unexplained infertility and recurrent miscarriages exhibit higher expression of collagen type I, MMP2 and TIMP1 (Jokimaa et al. 2002).

In the second experiment described in the present study, the transcriptome signature from day 6 uterine biopsies, all collected in the same cycle of the Al, was determined with particular focus on ECM remodeling pathways. This implies that, data on pregnancy outcome could be retrospectively linked with endometrial transcript characteristics. Samples were collected from contralateral uterine horn in relation to 
the pregnancy without a negative effect on pregnancy outcome as reported previously (Pugliesi et al. 2014). Main pathways on day $6 \mathrm{P}$ vs NP uterine tissue were related to ECM remodeling processes. Indeed, COL7A1 and $A D A M 12$, which are genes associated with extracellular matrix formation, belong to the top-20 list of genes with downregulated expression in the P uterus. In addition, MMP11 also had a higher expression in the NP group, which has been linked to cell proliferation properties. This is in line with a study conducted by Bauersachs and coworkers (2006) that indicated that the expression of collagen type I (COL1A1 and COL1A2) and collagen type VI (COL6A1) were reported to be higher in non-pregnant cows compared to pregnant cows. In accordance, COL1A2 was also more expressed in NP cows in the present study. Other genes that were differently expressed between $\mathrm{P}$ and NP day 6 endometrial tissue included ADAM12, ADAMTS1, TIMP3, BGN, EGFLAM, ANGPT4, AGRN, BMP4 and $M M P 2$. Furthermore, also an increased Decorin $(D C N)$ mRNA expression in the NP group and also concomitant upregulated levels of $T G F \beta 1$ and TGF $\beta 2$ were observed in the NP group compared to their $\mathrm{P}$ counterparts. Decorin is a leucine-rich proteoglycan associated with type I collagen fibrils in tissues to which TGF $\beta$ binds with high affinity in the ECM and in doing so neutralizes its activity. Thereby, Decorin acts as a reservoir of TGF $\beta$ in the extracellular milieu. TGF $\beta$ is a potent stimulator of collagen synthesis by increasing transcription and decreasing collagen degradation via reduced MMPs or enhanced TIMPs, thus favoring an accumulation of ECM and especially of collagen (Roberts et al. 1992, Brenner et al. 1994, Arici et al. 1996, Siwik \& Colucci 2004). Interestingly, the presented data are in line with human studies, in which uterine tumor formations, such as leiomyoma, are characterized by an increased synthesis and deposition of ECM proteins, mainly collagens type I and III as well as an increased mRNA abundance of MMP2 and MMP11 (Wolańska et al. 2004, Malik et al. 2010, Iwahashi \& Muragaki 2011). The increased expression of collagens, in combination with other differences observed in ECM related genes when comparing the low-fertile endometrial tissue, is suggestive for upregulated cell proliferation activities. In agreement, work performed by our group (Mesquita et al. 2015) suggests that early endometrial tissue of cows with lower probability for ongoing pregnancy are more permissive to proliferation and less favorable to activities related to cell differentiation.

When comparing the high-fertile (LF-LCL and P) and low-fertile (SF-SCL and NP) endometrial tissue from Experiment 1 and Experiment 2, respectively, a significant downregulated expression of genes involved of ECM remodeling pathways was noticed in both the high-receptive LF-LCL as well in the P endometrial tissue (shown in Table 7). These results suggest that ECM components should be appropriately expressed or inhibited, and it leads to the proposition that ECM overexpression could possibly inhibit the initial embryonic contact with maternal endometrial tissue, thereby prompting pregnancy failure. Several authors have indeed shown the importance of pre-ovulatory follicle size on pregnancy outcome (Vasconcelos et al. 2001, Perry et al. 2005, Baruselli et al. 2012). Here, our analysis suggested that as follicle size increases, expression of ECM remodeling genes change, which may imply that there is a specific ECM phenotype that more adequately supports fertility. However, it is curious that a set of genes was commonly regulated between the two models despite the fact that cows in Experiment 2 were selected to show similar concentrations of progesterone among individuals. It is tempting to speculate that both sex steroid-dependent and -independent mechanisms are in place to control ECM remodeling and its effects on embryo receptivity.

Both fertility models used in the present study might provide a useful tool to modulate and fine-tune, within physiological limits, the uterine 'receptive' environment and thereby influence the probability for ongoing pregnancy. Our main focus was the characterization of specific ECM signatures in bovine endometrial tissue during the early diestrus period; a timing that coincides with the process of bovine embryo arrival in the uterus. This is a highly crucial moment that needs further investigation as several studies identify this receptivity period as the reason for the dramatic incidence in embryonic losses in cattle industry.

In conclusion, early diestrus ECM remodeling events can be considered as key factors determining pregnancy outcome. The first set of experiments showed that specific endocrine profiles, that drive endometrial receptivity, also control ECM-related gene expression profiles and even phenotypic characteristics of the ECM in the tissue. The second experiment determined the ECM-related gene expression as potential predictors for probability of further pregnancy success. The overlapping set of genes being differently expressed in both fertility-related models highlights the importance of this matter and the potential to use the ECM remodeling data as tools to modulate receptivity and predict pregnancy outcome.

\section{Declaration of interest}

The authors declare that there is no conflict of interest that could be perceived as prejudicing the impartiality of the research reported.

\section{Funding}

This work was supported by LFEM (Projects \#210, 212 and 213) and Fundação de Amparo à Pesquisa do Estado de São Paulo (FAPESP; 2011/03226-4; 2012/04004-8). 


\section{Acknowledgements}

The authors thank Dr L A Silva from Universidade de São Paulo for the ultrasound instrument; F S Mesquita, V Van Hoeck, F D'Alexandri, A M Gonella-Diaza, M R França, R S Ramos, E Lopes, E R Araujo, M Sponchiado, M L Oliveira and Kauê Ribeiro da Silva for technical assistance; and the administration of the Pirassununga campus of the University of São Paulo for assistance in animal handling.

\section{References}

Alberts B, Johnson A, Lewis J, Raff $M$, Roberts $K$ \& Walter $P$ 2002 Molecular Biology of the Cell, 4th ed. New York, NY, USA: Garland Publishing.

Anders S \& Huber W 2010 Differential expression analysis for sequence count data. Genome Biology 11 R106. (doi:10.1186/gb-2010-1110-r106)

Arici A, MacDonald PC \& Casey ML 1996 Modulation of the levels of transforming growth factor beta messenger ribonucleic acids in human endometrial stromal cells. Biology of Reproduction 54 463-469. (doi:10.1095/biolreprod54.2.463)

Baruselli PS, Sá Filho MF, Ferreira RM, Sales JN, Gimenes LU, Vieira LM, Mendanha MF \& Bó GA 2012 Manipulation of follicle development to ensure optimal oocyte quality and conception rates in cattle. Reproduction in Domestic Animals 47 134-141. (doi:10.1111/j.14390531.2012.02067.x)

Bauersachs S, Ulbrich SE, Gross K, Schmidt SE, Meyer HH, Wenigerkind H, Vermehren M, Sinowatz F, Blum H \& Wolf E 2006 Embryo-induced transcriptome changes in bovine endometrium reveal species-specific and common molecular markers of uterine receptivity. Reproduction 132 319-331. (doi:10.1530/rep.1.00996)

Bazer FW \& Slayden OD 2008 Progesterone-induced gene expression in uterine epithelia: a myth perpetuated by conventional wisdom. Biology of Reproduction 79 1008-1009. (doi:10.1095/ biolreprod.108.072702)

Benjamini Y \& Hochber Y 1995 Controlling the false discovery rate: a practical and powerful approach to multiple testing. Journal of the Royal Statistical Society 57 289-300.

Binelli M, Scolari SC, Pugliesi G, Van Hoeck V, Gonella-Diaza AM, Andrade SC, Gasparin GR \& Coutinho LL 2015 The transcriptome signature of the receptive bovine uterus determined at early gestation. PLOS ONE 10 0122874. (doi:10.1371/journal.pone.0122874)

Boos A 2000 Immunohistochemical assessment of collagen types I, III, IV and VI in biopsy samples of the bovine uterine wall collected during the oestrous cycle. Cells Tissues Organs 167 225-238. (doi:10.1159/000016799)

Brenner DA, Rippe RA, Rhodes K, Trotter JF \& BreindI M 1994 Fibrogenesis and type I collagen regulation. Journal of Laboratory and Clinical Medicine 124 755-760.

Clark DE, Hurst PR, McLennan IS \& Myers DB 1993 Immunolocalization of collagen type I and laminin in the uterus on days 5 to 8 of embryo implantation in the rat. Anatomical Record 237 8-20. (doi:10.1002/ ar.1092370103)

Crawford HC \& Matrisian LM 1996 Mechanisms controlling the transcription of matrix metalloproteinase genes in normal and neoplastic cells. Enzyme Protein 49 20-37.

Curry TE \& Kevin GO 2001 Cyclic changes in the matrix metalloproteinase system in the ovary and uterus. Biology of Reproduction 64 1285-1296. (doi:10.1095/biolreprod64.5.1285)

Dadarwal D, Mapletoft RJ,Adams GP, Pfeifer LFM, Creelman C \& Singh J 2013 Effect of progesterone concentration and duration of proestrus on fertility in beef cattle after fixed-time artificial insemination. Theriogenology $\mathbf{7 9}$ 859-866. (doi:10.1016/j.theriogenology.2013.01.003)

Das SK, Yano S, Wang J, Edwards DR, Nagase H \& Dey SK 1997 Expression of matrix metalloproteinases and tissue inhibitors of metalloproteinases in the mouse uterus during the peri-implantation period. Developmental Genetics 21 44-54. (doi:10.1002/(SICI)15206408(1997)21:1\&lt;44::AID-DVG5\&gt;3.0.CO;2-8)
Dennis G Jr, Sherman BT, Hosack DA, Yang J \& Gao W 2003 DAVID: database for annotation, visualization, and integrated discovery. Genome Biology 4 3. (doi:10.1186/gb-2003-4-5-p3)

Egeblad M, Rasch MG \& Weaver VM 2010 Dynamic interplay between the collagen scaffold and tumor evolution. Current Opinion in Cell Biology 22 697-706. (doi:10.1016/j.ceb.2010.08.015)

Farrar JD \& Carson DD 1992 Differential temporal and spatial expression of mRNA encoding extracellular matrix components in decidua during the peri-implantation period. Biology of Reproduction 46 1095-1108. (doi:10.1095/biolreprod46.6.1095)

Forde N, Carter F, Fair T, Crowe MA, Evans AC, Spencer TE, Bazer FW, McBride R, Boland MP, O'Gaora P et al. 2009 Progesterone-regulated changes in endometrial gene expression contribute to advanced conceptus development in cattle. Biology of Reproduction 81 784-794. (doi:10.1095/biolreprod.108.074336)

Garbarino EJ, Hernandez JA, Shearer JK, Risco CA \& Thatcher WW 2004 Effect of lameness on ovarian activity in postpartum Holstein cows. Journal of Dairy Science $\mathbf{8 7}$ 4123-4131. (doi:10.3168/jds.S00220302(04)73555-9)

Gentleman RC, Carey VJ, Bates DM, Bolstad B, Dettling M, Dudoit S, Ellis B, Gautier L, Ge Y, Gentry J et al. 2004 Bioconductor: open software development for computational biology and bioinformatics. Genome Biology 5 80. (doi:10.1186/gb-2004-5-10-r80)

Guillomot M 1999 Changes in extracellular matrix components and cytokeratins in the endometrium during goat implantation. Placenta 20 339-345. (doi:10.1053/plac.1998.0385)

Hurst PR \& Palmay RD 1999 Matrix metalloproteinases and their endogenous inhibitors during the implantation period in the rat uterus. Reproduction, Fertility and Development 11 395-402. (doi:10.1071/ RD99021)

Irwin JC, Suen LF, Faessen GH, Popovici RM, Giudice LC 2001 Insulinlike growth factor (IGF)-II inhibition of endometrial stromal cell tissue inhibitor of metalloproteinase-3 and IGF-binding protein-1 suggests paracrine interactions at the decidua:trophoblast interface during human implantation. Journal of Clinical Endocrinology \& Metabolism $\mathbf{8 6}$ 2060-2064.

Iwahashi M \& Muragaki Y 2011 Increased type I and V collagen expression in uterine leiomyomas during the menstrual cycle. Fertility and Sterility 95 2137-2139. (doi:10.1016/j.fertnstert.2010.12.028)

Jarvelainen H, Sainio A, Koulu M, Wight TN \& Penttinen R 2009 Extracellular matrix molecules: potential targets in pharmacotherapy. Pharmacology 61 198-223. (doi:10.1124/pr.109.001289)

Jokimaa V, Oksjoki S, Kujari H, Vuorio E \& Anttila L 2002 Altered expression of genes involved in the production and degradation of endometrial extracellular matrix in patients with unexplained infertility and recurrent miscarriages. Molecular Human 8 1111-1116. (doi:10.1093/ molehr/8.12.1111)

Kim SH, Turnbull J \& Guimond S 2011 Extracellular matrix and cell signalling: the dynamic cooperation of integrin, proteoglycan and growth factor receptor. Journal of Endocrinology 209 139-151. (doi:10.1530/ JOE-10-0377)

Klein C, Bauersachs S, Ulbrich SE, Einspanier R, Meyer HH, Schmidt SE, Reichenbach HD, Vermehren M, Sinowatz F, Blum H et al. 2006 Monozygotic twin model reveals novel embryo-induced transcriptome changes of bovine endometrium in the preattachment period. Biology of Reproduction 74 253-264. (doi:10.1095/biolreprod.105.046748)

Love MI, Huber H \& Anders S 2014 Moderated estimation of fold change and dispersion for RNA-Seq data with DESeq2. bioRxiv. (doi:10.1101/002832)

Malik M, Norian J, McCarthy-Keith D, Britten J \& Catherino WH 2010 Why leiomyomas are called fibroids: the central role of extracellular matrix in symptomatic women. Seminars in Reproductive Medicine $\mathbf{2 8}$ 169-179. (doi:10.1055/s-0030-1251475)

Mamo S, Mehta JP, McGettigan P, Fair T, Spencer TE, Bazer FW \& Lonergan P 2011 RNA sequencing reveals novel gene clusters in bovine conceptuses associated with maternal recognition of pregnancy and implantation. Biology of Reproduction 85 1143-1151. (doi:10.1095/ biolreprod.111.092643)

Marbaix E, Donnez J, Courtoy PJ \& Eeckhout Y 1992 Progesterone regulates the activity of collagenase and related gelatinases $A$ and $B$ in human endometrial explants. PNAS 89 11789-11793. (doi:10.1073/ pnas.89.24.11789) 
Meneghetti M, Sá Filho OG, Peres RF, Lamb GC \& Vasconcelos JL 2009 Fixed-time artificial insemination with estradiol and progesterone for Bos indicus cows I: basis for development of protocols. Theriogenology 72 179-189. (doi:10.1016/j.theriogenology.2009.02.010)

Mesquita FS, Pugliesi G, Scolari SC, França MR, Ramos RS, Oliveira M, Papa PC, Bressan FF, Meirelles FV, Silva LA et al. 2014 Manipulation of the periovulatory sex steroidal milieu affects endometrial but not luteal gene expression in early diestrus Nelore cows. Theriogenology $\mathbf{8 1}$ 861-869. (doi:10.1016/j.theriogenology.2013.12.022)

Mesquita FS, Ramos RS, Pugliesi G, Andrade SC, Van Hoeck V, Langbeen A, Oliveira ML, Gonella-Diaza AM, Gasparin G et al. 2015 The receptive endometrial transcriptomic signature indicates an earlier shift from proliferation to metabolism at early diestrus in the cow. Biology of Reproduction 93 52. (doi:10.1095/biolreprod.115.129031)

Mishra B, Kizaki K, Koshi K, Ushizawa K, Takahashi T, Hosoe M, Sato T, Ito A \& Hashizume K 2010 Expression of extracellular matrix metalloproteinase inducer (EMMPRIN) and its related extracellular matrix degrading enzymes in the endometrium during estrous cycle and early gestation in cattle. Reproductive Biology and Endocrinology 8 60-71. (doi:10.1186/1477-7827-8-60)

Mitko K, Ulbrich SE, Wenigerkind H, Sinowatz F, Blum H, Wolf E \& Bauersachs S 2008 Dynamic changes in messenger RNA profiles of bovine endometrium during the oestrous cycle. Reproduction 135 225-240. (doi:10.1530/REP-07-0415)

Mott JD \& Werb Z 2004 Regulation of matrix biology by matrix metalloproteinases. Current Opinion in Cell Biology 16 558-564. (doi:10.1016/j.ceb.2004.07.010)

Nagase H, Visse R \& Murphy G 2006 Structure and function of matrix metalloproteinases and TIMPs. Cardiovascular Research 69 562-573. (doi:10.1016/j.cardiores.2005.12.002)

Osteen KG, Keller NR, Feltus FA \& Melner MH 1999 Paracrine regulation of matrix metalloproteinase expression in normal human endometrium. Gynecology Obstetrics Investigation 48 2-13. (doi:10.1159/000052863)

Peres RF, Claro I, Sá Filho OG, Nogueira GP \& Vasconcelos JL 2009 Strategies to improve fertility in Bos indicus postpubertal heifers and nonlactating cows submitted to fixed-time artificial insemination. Theriogenology $\mathbf{7 2}$ 681-689. (doi:10.1016/j.theriogenology.2009.04.026)

Perry GA, Smith MF, Lucy MC, Green JA, Parks TE, MacNeil MD, Roberts AJ \& Geary TW 2005 Relationship between follicle size at insemination and pregnancy success. PNAS 102 5268-5273. (doi:10.1073/pnas.0501700102)

Pugliesi G, Scolari SC, Mesquita FS, Maturana Filho M, Araújo ER, Cardoso D, Sales JN, Martin I, Sá Filho M, Bertan CM et al. 2014 Impact of probing the reproductive tract during early pregnancy on fertility of beef cows. Reproduction in Domestic Animal 49 35-39. (doi:10.1111/ rda.12345)

Pugliesi G, Santos FB, Lopes E, Nogueira É, Maio JR \& Binelli M 2016 Improved fertility in suckled beef cows ovulating large follicles or supplemented with long-acting progesterone after timed-Al. Theriogenology 85 1239-1248. (doi:10.1016/j.theriogenology.2015.12.006)

Reiss K \& Saftig P 2009 The 'adisintegrin and metalloprotease' (ADAM) family of sheddases: physiological and cellular functions. Seminars in Cell and Development Biology 20 126-137. (doi:10.1016/j. semcdb.2008.11.002)

Roberts AB, Mccune BK \& Spore B 1992 TGF-bold beta: regulation of extracellular matrix. Kidney International 41 557-559. (doi:10.1038/ ki.1992.81)

Robinson RS, Mann GE, Lamming GE \& Wathes DC 2001 Expression of oxytocin, oestrogen and progesterone receptors in uterine biopsy samples throughout the oestrous cycle and early pregnancy in cows. Reproduction 122 965-979. (doi:10.1530/rep.0.1220965)

Rodgers WH, Matrisian LM, Giudice LC, Dsupin B, Cannon P, Svitek C, Gorstein F \& Osteen KG 1994 Patterns of matrix metalloproteinase expression in cycling endometrium imply differential functions and regulation by steroid hormones. Journal of Clinical Investigation 94 946-953. (doi:10.1172/JCI117461)

Salilew-Wondim D, Hölker M, Rings F, Ghanem N, Ulas-Cinar M, Peippo J, Tholen E, Looft C, Schellander K \& Tesfaye D 2010 Bovine pretransfer endometrium and embryo transcriptome fingerprints as predictors of pregnancy success after embryo transfer. Physiologic Genomics 42 201-218. (doi:10.1152/physiolgenomics.00047.2010)

Schenk S \& Quaranta V 2003 Tales from the crypt [ic] sites of the extracellular matrix. Trends in Cell Biology 13 366-375. (doi:10.1016/ S0962-8924(03)00129-6)

Schmidt S \& Friedl P 2010 Interstitial cell migration: integrin-dependent and alternative adhesion mechanisms. Cell and Tissue Research 339 83-92. (doi:10.1007/s00441-009-0892-9)

Schroen DJ \& Brinckerhoff CE 1996 Nuclear hormone receptors inhibit matrix metalloproteinase (MMP) gene expression through diverse mechanisms. Gene Expression 6 197-207.

Siddiqui MA, Gastal EL, Gastal MO, Almamun M, Beg MA \& Ginther OJ 2009 Relationship of vascular perfusion of the wall of the preovulatory follicle to in vitro fertilisation and embryo development in heifers. Reproduction 137 689-697. (doi:10.1530/REP-08-0403)

Siwik DA \& Colucci WS 2004 Regulation of Matrix metalloproteinases by cytokines and reactive oxygen/nitrogen species in the myocardium. Heart Failure Reviews 9 43-51. (doi:10.1023/ B:HREV.0000011393.40674.13)

Skinner JL, Riley SC, Gebbie AE, Glasier AF \& Critchley HO 1999 Regulation of matrix metalloproteinase-9 in endometrium during the menstrual cycle and following administration of intrauterine levonorgestrel. Human Reproduction 14 793-799. (doi:10.1093/ humrep/14.3.793)

Sluijter JPG, de Kleijn DPV, \& Pasterkamp G 2006 Vascular remodeling and protease inhibition - bench to bedside. Cardiovascular Research 69 595-603. (doi:10.1016/j.cardiores.2005.11.026)

Snoek PAM, van Beurden \& JW Von den Hoff 2005 Zymographic techniques for the analysis of matrix metalloproteinases and their inhibitors. BioTechniques 38 73-83. (doi:10.2144/05381RV01)

Ulbrich SE, Meyer SU, Zitta K, Hiendleder S, Sinowatz F, Bauersachs S, Büttner M, Fröhlich T, Arnold GJ, Reichenbach HD et al. 2011 Bovine endometrial metallopeptidases MMP14 and MMP2 and the metallopeptidase inhibitor TIMP2 participate in maternal preparation of pregnancy. Molecular Cellular Endocrinology 332 48-57. (doi:10.1016/j. mce.2010.09.009)

Vasconcelos JL, Sartori R, Oliveira HN, Guenther JG \& Wiltbank MC 2001 Reduction in size of the ovulatory follicle reduces subsequent luteal size and pregnancy rate. Theriogenology 56 307-314. (doi:10.1016/S0093691X(01)00565-9)

Wolańska M, Sobolewski K, Bańkowski E \& Jaworski S 2004 Matrix metalloproteinases of human leiomyoma in various stages of tumor growth. Gynecology Obstetrics Investigation 58 14-18. (doi:10.1159/000077177)

Yamada O, Todoroki J, Takahashi T \& Hashizume K 2002 The dynamic expression of extracellular matrix in the bovine endometrium at implantation. Journal of Veterinary Medicine Science 64 207-214. (doi:10.1292/jvms.64.207)

Zhang J \& Salamonsen LA 2002 In vitro evidence active matrix metalloproteinase in human endometrium supports their role in tissue breakdown at menstruation. Journal of Clinical Endocrinology and Metabolism 87 52346-52351. (doi:10.1210/jc.87.5.2346)

Received 2 May 2016

First decision 25 May 2016

Revised manuscript received 26 September 2016

Accepted 17 October 2016 